DIW BERLIN

Discussion Papers

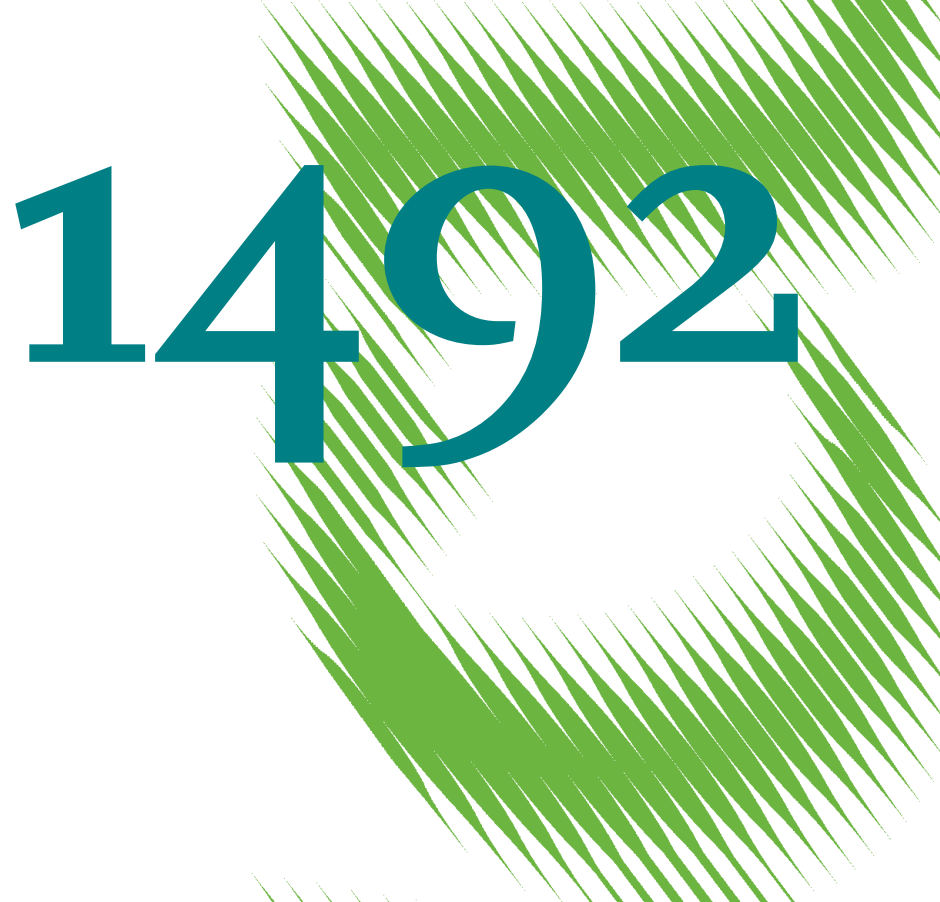

A Welfare Analysis of the Electricity Transmission Regulatory Regime in Germany 
Opinions expressed in this paper are those of the author(s) and do not necessarily reflect views of the institute.

IMPRESSUM

(C) DIW Berlin, 2015

DIW Berlin

German Institute for Economic Research

Mohrenstr. 58

10117 Berlin

Tel. +49 (30) $89789-0$

Fax +49 (30) $89789-200$

http://www.diw.de

ISSN electronic edition 1619-4535

Papers can be downloaded free of charge from the DIW Berlin website:

http://www.diw.de/discussionpapers

Discussion Papers of DIW Berlin are indexed in RePEc and SSRN:

http://ideas.repec.org/s/diw/diwwpp.html

http://www.ssrn.com/link/DIW-Berlin-German-Inst-Econ-Res.html 


\title{
A Welfare Analysis of the Electricity Transmission Regulatory \\ Regime in Germany ${ }^{1}$
}

\author{
Claudia Kemfert ${ }^{2}$, Friedrich Kunz ${ }^{3}$ and Juan Rosellón ${ }^{4}$
}

\begin{abstract}
We analyze the current regulatory regime for electricity transmission in Germany, which combines network planning with both cost-plus and revenue-cap regulations. After reviewing international experiences on transmission investment, we first make a qualitative assessment of the overall German regime. The German TSOs have in general incentives to overinvest and inefficiently inflate costs. We further develop two models to analyze the transmission planning process. In the first model there is no trade-off between transmission expansion and generation dispatch. This is a modeling set-up similar to the one actually used in the German transmission planning (Netzentwicklungsplan). A second model alternatively allows for such a trade-off, and thus represents an optimal way of transmission network planning. Simulations with the two models are carried out and compared so as to illustrate the amount of excessive transmission capacity investment and welfare losses associated with the current regime.
\end{abstract}

Keywords: Transmission planning, nodal prices, congestion management, electricity, Germany.

JEL codes: L50; L94; Q40

\footnotetext{
${ }^{1}$ Research developed under the Mercator Project: Model-based analyses for the electricity sector design to favor the integration of renewable energies in the energy transformation (MASMIE). A previous version of this paper was presented at the Symposium on Energy Markets and Sustainability, Chair of Energy Sustainability-IEB, University of Barcelona, February $3^{\text {rd }}, 2015$, in Barcelona, Spain. We thank the valuable feedback from the conference participants.

${ }^{2}$ DIW Berlin, Department of Energy, Transportation, Environment, Mohrenstraße 58, 10117 Berlin, Germany, ckemfert@diw.de.

${ }^{3}$ DIW Berlin, Department of Energy, Transportation, Environment, Mohrenstraße 58, 10117 Berlin, fkunz@diw.de. Friedrich Kunz acknowledges financial support from the Mercator foundation within the project MASMIE.

${ }^{4}$ CIDE, Department of Economics, Carretera México-Toluca 3655 Col. Lomas de Santa Fe 01210 México, D.F. juan.rosellon@cide.edu; and DIW Berlin, Department of Energy, Transportation, Environment, Mohrenstraße 58, 10117 Berlin, jrosellon@diw.de. Juan Rosellón acknowledges financial support from the Mercator foundation within the project MASMIE.
} 


\section{Introduction}

Worldwide, different regulatory regimes for electricity transmission are in place. There is usually a question on which regime might provide the best incentives to attract investment so that grids are expanded in a welfare-efficient way. Europe is mainly characterized by Transmission System Operators (TSOs) that own networks, plan the grid's expansion, and carry out the operation of the system (including generation dispatch). In some countries (such as the Netherlands) incentive regulation is additionally used to regulate TSOs network investments. In other countries (Belgium and Germany), a mixed of cost-plus regulation for investment costs, and incentive regulation for operation and maintenance costs, is in place.

In this paper, we analyze the current regulatory regime for electricity transmission in Germany, which is going through an energy transition (Energiewende) reform process. ${ }^{5}$ Both its transmission planning regime and its prevailing combined revenue-cap cost-plus regulations are analyzed. This task is carried out based on a regulatory-economics focus. We first carry out a qualitative overall assessment of the joint effects of the planning and regulatory schemes for transmission investment. We then further focus in a more formal analysis of the German planning for development of the grid (Netzentwicklungsplan-NEP). With such a purpose, a transition in the German electricity industry of the current uniform pricing scheme to a nodal-pricing system is simulated. In practice, such a change in the German price system might be implemented through a corresponding allocation of financial hedges, such as financial transmission rights (FTRs), that achieve distributional efficiency among the different involved economic agents (loads, transmission companies and generators). ${ }^{6}$ We develop then two models. One is a "decoupled" model where there is no trade-off between transmission expansion and generation dispatch; a modeling set-up similar to the one used in the German transmission development planning. A second "integrated" model allows for such a trade-off, and thus represents an optimal way of transmission capacity expansion. Simulations with the two models are carried out and compared so as to gauge the amount of over investment in capacity associated with the current regime.

\footnotetext{
${ }^{5}$ The Energiewende includes an $80 \%$ share of renewable energy sources (RES) in gross electricity consumption by 2050 , improvements in energy efficiency (e.g., primary energy consumption is to fall by $50 \%$ by 2050 ), as well as developments in energy system management such as smart grids and flexibility options.

${ }^{6}$ See Kunz et al. 2014.
} 
Our main purpose in this paper is to motivate a research agenda that we think is interesting both from an academic point of view as well as from a practical perspective. Our assessment of the German transmission investment regime could be of interest for regulators and policy makers willing to improve market price signals and regulatory systems in the power sector. This paper is organized as follows. In section 2, we carry out a literature review on conceptual issues related to optimal transmission investment and regulation. In section 3, we present different institutional settings for electricity transmission, and how they are implemented internationally. In section 4 we analyze in detail the case of the German transmission regulatory regime. We first carry out its qualitative assessment in sections 4.1 through 4.3. We further develop in section 4.4 a modeling set-up to compare the German regime, characterized by a transmission planning regime decoupled from generation dispatch, with a benchmark model which integrates the decisions of transmission expansion and generation (re)dispatch. Section 5 concludes with some key remarks and proposes avenues for further research.

\section{Optimal Transmission Expansion: Literature Review}

In this section we analyze literature on conceptual issues related to optimal transmission investment and regulation.

\subsection{Price-Cap vs. Cost-Plus Regulation}

Brunekreeft and Borrmann (2011) carry out a complete-information analysis of pricecap and cost-plus regulation on the timing of lumpy investment by a natural monopoly. They show that, under price-based regulation, investment does not affect own regulated prices while cost-based regulation investment triggers price changes. They further model both replacement investment and expansion investment through variable-cost increases and demand growth increases, respectively. By comparing the cases of a social welfare maximizer, an unregulated monopolist, a price-based regulated monopolist and a cost-based regulated monopolist they conclude that, for both the increasing variable-cost and demand-growth cases, cost-based regulation accelerates investment compared to price-based regulation.

A similar result is obtained by Brito and Rosellón (2011) in regulated natural gas pipelines when investment is lumpy and the demand for gas is stochastic. They formulate the problem from the standpoint of consumers that face incomplete markets. 
They find that for "reasonable" parameter values consumers prefer to pay for excess capacity rather than bearing the risk of congestion. Since the demand for gas is very inelastic, the welfare losses associated from small deviations from a first-best optimum (using price-cap regulation) are minimal. This implies that a gas pipeline system can be regulated with a cost-plus rule without any significant loss of welfare.

Schill et al (2015), however, reach opposite conclusions. They test different regulatory regimes under wind supply and fluctuating demand and find that, in terms of welfare convergence, incentive price-cap regulation is a superior alternative to cost-plus or no-regulation. Furthermore, under a transformation process of the generation system towards renewable technologies Egerer et al (2015) also find that price-cap regulation is superior in promoting investment in electricity networks compared to cost-plus regulation, as long as the proper weights are used in the price-cap formula.

\subsection{Price-Cap vs. Revenue-Cap Regulation}

As opposed to price-cap regulation, the German electricity transmission network is subject to revenue-cap regulation. What is the state of the literature regarding such a regime? Jamasb and Pollitt (2001) argue that the choice of revenue-cap rather than price-cap means that the regulated firm does not face major quantity risk. This could be appropriate in cases where the quantity demanded is largely outside the control of the regulated firm (such as electricity distribution), and where costs may be insensitive to short-term variations in quantity demanded.

Crew and Kleindorfer (1996) show that revenue caps do not necessarily cap prices. In fact, they might even provide incentives for price increases above the unregulated monopoly level. Lanz (2005) further show that this result is robust to twopart tariff pricing. Revenue-cap_regulation could then imply decreases in consumer surplus, and not be cost minimizing as opposed to price-cap regulation (Vogelsang, 2001, and Hogan et al, 2010). However, it must be pointed out that revenue-cap and price-cap regulations usually coincide when output is ex-ante given (i.e., not a choice variable). This is typically characteristic of regimes with ex-ante process of transmission planning (as it will be analyzed in section 3 of this paper). 


\subsection{Optimal Transmission Expansion}

The issue of optimal transmission expansion has been addressed through a range of different regulatory schemes and mechanisms that have been proposed and applied (e.g., Léautier 2000, Kristiansen and Rosellón 2006, Tanaka 2007, Léautier and Thelen 2009, Hogan et al. 2010). Finding optimal regulatory mechanisms is difficult given the specific physical characteristics of electricity networks like negative local externalities due to loop flows, i.e. electricity flows obeying Kirchhoff's laws. One approach to transmission expansion has been traditional central planning, either carried within a vertically integrated utility or by a regulatory authority. A usual alternative has been cost-of-service regulation. In contrast, transmission decisions could also be determined in a decentralized non-regulated way.

The Hogan-Rosellon-Vogelsang price-cap mechanism (Hogan et al. 2010, HRV) is an example of a decentralized regulatory regime which combines merchant and regulatory structures to promote the expansion of electricity networks. The HRV model is technically a bi-level programming model within an institutional structure with an independent system operator (ISO) and an independent transmission company (Transco) (see fig. 1). There is an upper level (which models the profit-maximizing problem the Transco), and a lower level (a power flow model of welfare-maximizing generationdispatching ISO). A price-cap over the two parts of the Transco's tariff is in place in the upper level.

The amount of transmission capacity to be expanded is initially first chosen in the upper level problem by the Transco. This provides the capacity limit for the capacity constraint in the line-flow lower level. The optimal power flows (including impedances) --as well as injections in the energy balance constraints-- are then determined still in the lower level. The optimal demands and generation quantities are further established in the objective function of the lower level. This then allows the determination of optimal transmission revenues in the objective function of the upper level problem and, subsequently, the optimal value of the fixed fee according to the price-cap constraint of the upper level.

The HRV model thus defines an algorithm that could potentially be implemented by some of the large electricity markets in the US Northeast which have the necessary 
institutions to apply this approach, including an ISO managing the wholesale market, nodal pricing, as well as auctions for financial transmission rights (FTRs). ${ }^{7}$

Fig. 1

Source: own elaboration

\section{A combined merchant-regulatory mechanism} (algorithm)

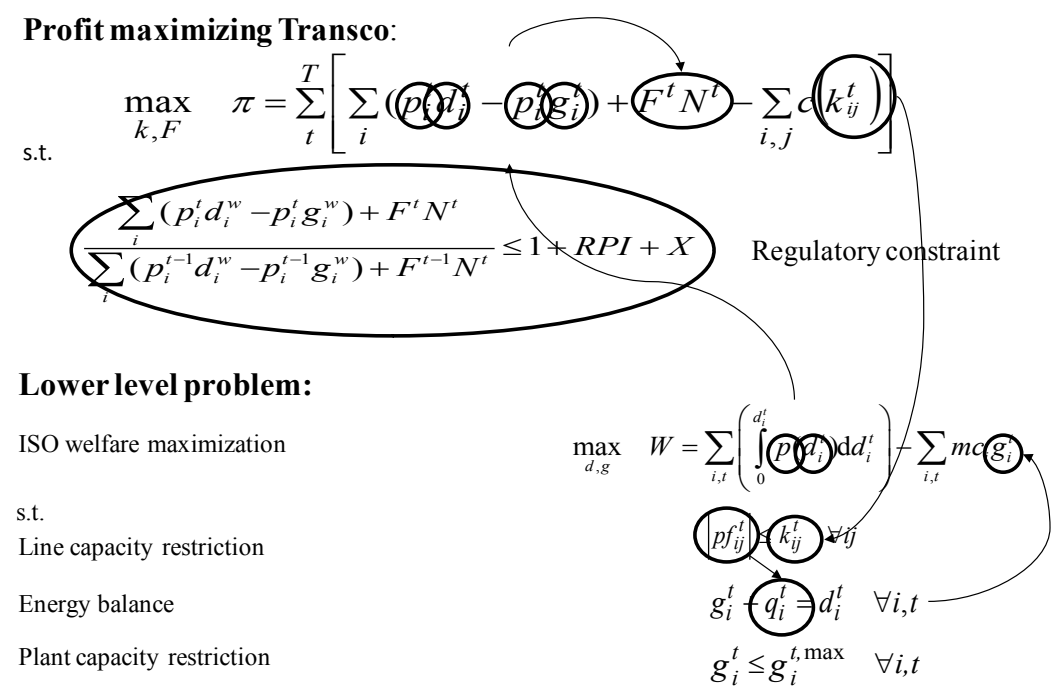

$k_{i j}^{t}=$ line capacity between node $i$ and node $j$ at time $t$.

$F^{t}=$ fixed fee at time $t$.

$d_{i}^{t}=$ demand at node $i$ at time $t$.

$g_{i}^{t}=$ generation at node $i$ at time $t$.

$g_{i}{ }^{\max }=$ available generation capacity

$N^{t}=$ number of consumers at time $t$.

$p()=$. demand function.

$\mathrm{c}(k)=$ transmission cost function in terms of capacity.

$R P I=$ inflation adjustment factor

$X=$ efficiency adjustment factor

$w=$ weight

$m c_{i}=$ marginal generation costs at node $i$.

$p f_{i j}=$ power flow on the line connecting $i$ and $j$

$q_{i}=$ net injections

${ }^{7}$ See Rosellón et al. (2011) 


\subsection{Optimal Transmission Expansion under Renewable-Integration}

There is scarce research on optimal transmission regulation under realistic demand patterns and large-scale renewable integration. This issue is particularly addressed in Schill et al (2015), and Egerer et al (2015). Schill et al (2015) carry out a comparison of different regulatory regimes under intermittent renewable generation, and fluctuating demand. They basically compare the HRV price-cap method with cost-plus regulation, and find that the HRV formula is welfare superior to cost-plus or no-regulation. The implementation of the HRV model is basically carried out giving more time resolution in both the upper and lower levels of the HRV bi-level program, so as to address both fluctuating supply and demand, which are characteristic of systems with a high-share of renewable technology. The welfare superiority of HRV regulation is shown to prevail in this paper under various sensitivities on the number of regulatory periods, level of transmission extension costs, amounts of wind output, social-discount rates and line reactances.

Egerer et al (2015) analyze the transformation of power systems toward renewables (e.g., wind substituting coal generation). They assume different scenarios on the implied effects of this transformation process on transmission network congestion. They find that the performance of price-cap incentive regulation depends on the different types of price weights that are used in the price-cap regulatory formula. While ideal weights (i.e., weights that prevail in the steady state welfare-benchmark equilibrium) make prices converge to optimality, Laspeyres (previous-quantity) weights lead to overinvestment and (current-period) Paasche weights worsen these effects. Notwithstanding, they also show that excessive non-optimal investments might be avoided through a proper combination of weights. For instance, using average Laspeyres-Paasche weights might be a reasonable overall incentive strategy in the context of permanently or temporarily increasing network congestion. Likewise, under certain assumptions (such as non-ideal weights), cost-plus regulation might provide more satisfactory results than price-cap regulation. ${ }^{8}$

\footnotetext{
${ }^{8}$ See Egerer et al 2015, p. 18 (table 2).
} 


\section{The TSO and ISO Regimes for Transmission Investment: International Experiences}

\subsection{The TSO Regime}

One institutional approach for electricity transmission is the TSO regime, where system operation and ownership of the grid are integrated into a single company. There is typically a regulator which sets up a regulatory constraint on transmission tariffs, as well as a planning entity (that could be, for instance, an Energy Ministry). The usual steps for decision making on transmission expansion and investment under the TSO regime involve the following sequential steps:

First step: An exogenous definition of expected generation supply with certain technology mixes, and demand capacity needs, is carried out by the planning entity through market studies under different scenarios.

Second step: Given the generation-demand assumptions, a national transmission development plan (NDP) is carried out by the TSO in order to derive its proposed expansion of the transmission grid. The NDP is typically reviewed by stakeholders, and approved by the regulator

Third step: Given the NDP, the TSO carries out investment under the regulatory constraint, which may take the form of cost-plus or incentive regulation. Incentive regulation might take various forms: price caps, revenue caps, benchmarks, two-part tariff regulation and, even, a menu of contracts.

\subsection{ISO Regime with Planning}

An opposite institutional approach for electricity transmission is the IndependentSystem-Operator regime that only takes care of the system-operation activities, while the ownership of the grid belongs to a Transco. There is again a regulator which sets up a regulatory constraint on transmission tariffs, as well as a planning entity. The usual steps for decision making on transmission expansion and investment under this regime are:

First step: An exogenous definition of expected generation supply with certain technology mixes, and demand capacity needs, is carried out by the planning entity through market studies under different scenarios. 
Second step: Given such generation assumptions, the NDP is carried out by the ISO, typically using a power-flow model, in order to simultaneously derive the optimal generation dispatch and transmission expansion (as in the welfare-benchmark cases in Rosellón and Weigt, 2011, and Schill et al, 2015).

Third step: Given the NDP, the Transco carries out investment under the regulatory constraint, which again may take the form of cost-plus or incentive regulation.

\subsection{ISO Regime without Planning}

Another more extreme approach (which has not yet been tried in practice) would be the set-up of the HRV model proposed in Hogan et al (2010), where the expansion of the transmission grid is purely incented through price-cap regulation without a previous planning process. The ISO, the Transco, and the regulator interrelate in an environment with nodal-pricing and FTRs, so that decision making follows the next steps:

First step: A pre-existing network and point-to-point transmission prices that the Transco has charged up to the present are in place.

Second step: The regulator sets the (incentive) regulatory pricing constraint.

Third step: The Transco collects information about generation supply and electricity demand at all relevant geographical locations (or at each node).

Fourth step: The Transco invests in grid capacity.

Fifth step: The Transco auctions off point-to-point FTRs, based on the available grid capacity.

Sixth step: The ISO asks for (sequences of) bids from generators and loads at each node and then calculates nodal prices. Loads (ex post) pay the ISO according to their last bids and generators receive payment of their last bids in such a way that markets always clear. The owners of FTRs receive as congestion payments the difference between what loads pay, and what generators receive. Any excess congestion payments that cannot be allocated to an FTR (because less FTRs were sold than the point-to-point transmission available) go to the Transco.

Eighth step: Fixed fees are then calculated from the regulatory constraint, based on congestion charges, and are paid by the loads. 


\subsection{European Experiences on Transmission Regulation}

A brief review of European regimes for electricity transmission expansion reveals that the combination of a TSO regime, with planning of grid expansion and revenue-cap regulation, is common across many country electricity systems. The basic logic is that the planning process provides first the input on forecasted generation output, from where the transmission capacity needs are calculated within a power-flow model. The revenue-cap regulation scheme applied thereof to incentivize investment efficiency in operation and maintenance expenditures (OPEX) --combined in most cases with costplus regulation for new investments-- is thus based on a given transmission throughput. In such a case, revenue-cap regulation in fact coincides with price-cap regulation inheriting its incentive properties. It must be mentioned that, in most countries, regulatory schemes are complemented with other measures that provide costminimizing incentives, or help to handle risk. In the latter, adjustments to compensate the TSO for the difference between forecasted and actual needed transmission capacities are usually considered.

In Belgium and Germany the regulatory scheme used in the third step described in 3.1 is cost-plus regulation for new capacity investments, and revenue-cap for operation and OPEX. In France, incentive regulation is used for both OPEX and capital expenditures (CAPEX) with a revenue-cap over two-part tariffs for new capacity investments, while in the Netherlands incentive revenue-benchmark regulation (based on other European TSOs) for expansion investments, and revenue-cap for OPEX, is in place. In Great Britain, a relatively innovative regulation scheme is used, which is a mix of cost-plus and incentive regulation with emphasis on resource adequacy, innovation, and incentives to improve outputs to consumers (RIIO). RIIO also includes a menu of contracts to incentivize self-selection by the TSO.

We now review in some more detail the planning and regulation schemes for transmission investment within some European countries. ${ }^{9}$

\section{Belgium}

The Belgian TSO, Elia, carries out the planning of the Belgian electricity network based on various scenarios. The different scenarios reflect developments in electricity consumption, fossil and renewable generation, and nuclear phase-out. A generation plan then defines the assumptions on generation outputs that later serve as input for the TSO

\footnotetext{
${ }^{9}$ The case of Germany is analyzed in section 4 .
} 
to undertake market and grid expansion simulations to elaborate a national grid development plan (NGDP), considering technical and least-cost criteria on the development of interconnections integration of renewable-energy-source (RES) units and other units, as well as network reinforcement. The NGDP contains both short-term plans, as well as mid/long term plans (2010-2020). The Belgian regulator, CREG, carries out consultations to validate the NGDP.

The subsequent Belgian regulatory regime for electricity transmission is structured in four-year periods, and it is a based on a revenue-cap mechanism. This regime makes a distinction between non-controllable costs, including capital investments, which are basically passed through to consumers based on a cost-plus regime. The controllable costs are mainly OPEX and are adjusted with $X$-efficiency and

productivity factors. The Belgian regulatory basic system for electricity transmission is similar to the German one, in terms of the way it defines its structure of incentives. However, CREG also applies other measures to ensure that proper grid investments are carried out as well as to help with the TSO's handling of risk. On the former issue, a year-two incentive scheme is applied ex-post to part of CAPEX on replacement and reliability investments (based on a fund of approximately $€ 5$ million). On the latter issue, if the expected volume differs from the realized volume, a correction factor is applied ex post to ensure that ELIA is remunerated as expected.

\section{France}

The French TSO, RTE, must provide every year a ten-year national transmission development plan based on projected electricity demand and generation supply. The generation forecasts (which are public, and also consider the connection to the grid of RES units) are prepared every two years by RTE and the energy regulator (CRE). Given these generation assumptions, RTE develops its network expansion plan through a model that calculates welfare benefits against saved congestion costs, the value of avoided lost load, and the decrease of network losses. RTE then drafts a version of this transmission development plan (which is not public) that is put to consultation with transmission users and, later, with the general public. The three year section of the development plan is binding for RTE.

The French regulatory regime is also based on a four-year revenue-cap mechanism. The TSO's regulated activities include operation and investments following a "building-block" approach, so that the revenue cap makes a distinction between 
forecasted OPEX costs and CAPEX costs. These are controllable costs (controlled by the revenue cap) which are also subject to an X-efficiency factor. Non-controllable costs are passed through in tariffs through a cost-plus mechanism. In particular, new interconnections will rely on a new two-part incentive mechanism: a fix-part premium that aims to increase welfare at a European level (considering increase in cross-border flows, impacts on national prices and security of supply), and a variable-part premium that would incentivize that the interconnection provides a maximum of additional flows.

\section{The Netherlands}

Tenne $\mathrm{T}$ owns and operates the Dutch transmission system, and biannually publishes a seven-year capacity plan. It also creates a Vision-2030 public report, which provides long-term scenarios on economic growth, RES power penetration developments (mainly wind), generation locations within the Netherlands (onshore and coastal), and global demand for fossil fuels. Likewise, quantitative estimates on peak load and electricity generation capacity are carried out, together with different alternatives for demand and supply adjustments. Imports from Belgium and Germany are also added in the scenario analysis. For each of these scenarios, Tenne $\mathrm{T}$ carries out power-flow calculations to determine transmission capacity needs according to $(n-0),(n-1)$, and even $(n-2)$ criteria. These calculations are later integrated into a national electricity supply plan that is legally binding.

The Dutch regulatory design for electricity transmission is based on three-year revenue caps: one cap for total expenditures (TOTEX) with an RPI-X adjustment, and another cap for system-operation costs (which includes an incentive factor for the deviation of actual and expected costs). The first cap is subject to an X-efficiency factor which considers the original two-year lagged base costs of the TSO, and assesses the targeted costs at the end of the regulatory period. These targeted costs are based on a comparison of several TSOs, and takes as benchmarks the average of the three bestperforming firms. ${ }^{10}$ The $\mathrm{X}$-factor also considers the general technological progress within the sector. A complementary "risk reduction" term is applied for expansion investments that were not included in the original revenue cap. The costs of such investments are integrated in the tariff when assets are completed with a two-year lag.

\footnotetext{
${ }^{10}$ In 2013 , Tenne $\mathrm{T}$ was considered to have had an inefficiency of $\underline{40 \%}$ with respect to other efficient European TSOs.
} 


\section{Great Britain}

There are three transmission owners in Great Britain: National Grid Electricity Transmission, Scottish Power Transmission Limited, and Scottish Hydro-Electric Transmission Limited. They are required to submit a network development plan to the regulator, Ofgem, prior to each regulatory period. National Grid publishes each year multiple scenarios regarding spatial distribution of generation and demand, which are then subject to stakeholder consultation. The scenarios extend in detail to the year 2030 and, with a more general perspective, up to 2050. After the scenario development, a market simulation to plan the grid expansion is carried out. These simulations are performed following two criteria: a "security" (energy balance) criterion, and an "economic" (cost-benefit) criterion. ${ }^{11}$ The cost-benefit analysis ${ }^{12}$ includes the consideration of cost forecasts on transmission investment, constraints and transmission losses. The network development outcomes are then published in a ten-year national grid plan (ETYS) which, after consultation and consistency check with the regulatory network scheme (RIIO) ${ }^{13}$, the ETYS will be the basis of the National Grid's (nonbinding) business plan sent to Ofgem.

The new regulatory scheme used in Great Britain for transmission expansion is then RIIO. An eight-year revenue cap ${ }^{14}$ seeks to stress incentives to improve services and outputs to consumers (such as GHG emissions and reliability), innovation and longterm cost minimization. The revenue cap follows a TOTEX approach, so that a part of the TOTEX is capitalized ("slow money") and is paid as a 45-year depreciation of assets. The rest of TOTEX and non-controllable OPEX costs are passed through and paid yearly ("fast money"). A two-year lag and an inflation adjustment factor are also applied. Likewise, a cost efficiency scheme is further applied based on a menu of contracts that seek that the firm reveals its private-information on targeted costs. Additionally, the revenue cap might also be adjusted according to changes in investment drivers, including changes in the volume of expected generation and demand connections, and additional capacity needed to relieve network constraint.

\footnotetext{
${ }^{11}$ The former criterion seeks that demand is met without imports or from intermittent resources. The latter criterion should allow that sufficient transmission capacity is in place to bring RES generation to load centers.

${ }^{12}$ This cost-benefit analysis is made public.

${ }^{13}$ RIIO stand for: Revenue Incentives Outputs.

${ }^{14}$ With potential four-year revisions.
} 


\subsection{Other International Experiences}

Internationally, the ISO regime is popular in many countries within the Americas (such as Argentina, Chile, Brazil and, very recently, Mexico), US states (Texas, California, New York, New England, Pennsylvania-New Jersey-Maryl (PJM), and various MidWest states), Canadian provinces (Ontario, Alberta), Australia, and even some European countries such as Ireland and Switzerland. Pollit (2012) provides details on each one of these regimes. ${ }^{15}$ The ISO in these countries usually follow an institutional, planning and regulatory logic as described in 3.2 above.

The ISOs are in practice non-for-profit organizations that have generally helped to develop liberalized markets relying on sophisticated economic instruments (e.g., as nodal prices and FTRs)in order to deal with transmission congestion management issues. In the case of the PJM, New England, South West, Mid-West, New Brunswick (Canada) and Australian systems, the ISO operates at a multi-state level. For example, the PJM ISO includes areas in Delaware, Illinois, Indiana, Kentucky, Maryland, Michigan, New Jersey, North Carolina, Ohio, Pennsylvania, Tennessee, Virginia, West Virginia. Additionally, in countries as Chile and Argentina both the ISO and transmission operator are ownership unbundled from the rest of the system.

\section{The German Electricity-Transmission Regulatory Regime}

\subsection{The Regulatory Formula}

Germany follows a TSO approach with planning where grids are owned by four different TSOs. Cost-plus regulation is used to regulate capacity-expansion costs. Expansion transmission factors subject to this regulation are permanently non influenceable costs (PNIC) which include congestion rents, and investment budget (IB) costs. IB costs are composed by investments costs from projects approved by BNetzA (the federal network regulator) for expanding transmission systems. PNIC costs are then passed through directly in the consumer tariff.

Revenue-cap regulation is in turn mainly applied to operation and maintenance costs. Such costs include temporary non-influenceable and influenceable costs (TNIC+IC, respectively), but also some CAPEX for the assets in the regulated asset

\footnotetext{
${ }^{15}$ See Pollit (2012), p. 34 (figure 1).
} 
base. TNIC + IC are applied a TOTEX revenue-cap with both efficiency and productivity targets.

The detailed German regulatory formula looks like:

$E O_{t}=K A_{d n b, t}+\left(K A_{v n b, 0}+\left(1-V_{t}\right) K A_{b, 0}\right) \cdot\left(V P I_{t} / V P I_{0}-P F_{t}\right) E F_{t}+Q_{t}+\left(V K_{t}-V K_{0}\right)+S_{t}$

where:

$V_{t}=$ distribution factor for the reduction of the inefficiency (inefficiency needs only to be decreased fully at the end of the regulatory period or, for the first period, after the end of the second regulatory year).

$K A_{v n b, 0}=$ efficient costs (not influenceable at least in the current regulatory period).

$K A_{b, 0}=$ inefficient costs (influenceable in the current regulatory period).

$V K_{t}=$ volatile part of cost (e.g. lost head).

$S_{t}=$ balance for the regulatory account.

$b K=$ inefficient costs (influenceable in the current regulatory period) $\left(K A_{b, 0}\right)$.

$v n b K=$ efficient costs (not influenceable at least in this period) $\left(K A_{v n b, 0}\right)$.

$d n b K=$ not influencable costs $\left(K A_{d n b, t}\right)$.

In this formula, yearly adjustments are then made for:

- Inflation $V P I_{t} / V P I_{0}$.

- $\quad$ Not influencable costs $K A_{d n b, t \text {. }}$

- $\quad$ Quality element $Q_{t}$.

- $\quad$ Coverage factor (Erweiterungsfaktor, $E F_{t}$ ) for extension of the network, which applies for distribution only.

\subsection{Generation Scenarios and Transmission Planning}

The combined cost-plus revenue-cap regime used in Germany relies on transmissionnetwork planning since the amendment of the electricity law $(E n W G)$ in 2011. This planning process includes generation and demand scenario definitions, and the network development plan NEP. Based on these generation-forecast scenarios, the TSOs develop an initial draft of the $N E P$, which is then published for consultation with stakeholders, and finally approved by regulator, BNetzA. 
As opposed to Rosellón and Weigt (2011), and Schill et al (2015), the NEP is determined using a program that is independent from generation-power market dispatch. Although its results are publicly disclosed, the specific NEP programming model used is, to our knowledge, not public information. The whole planning process is repeated yearly for a time horizon of 10-20 years. The TSOs' role is then to carry out such projects, and charge prices subject to combined regulatory cost-plus revenue-cap constraint.

\subsection{Assessment}

DENA-Verteilnetzstudie (2012) assessed the German electricity-transmission regulatory regime. They estimated a network investment requirement of ca. $€ 27-€ 42$ billion up to 2030. This study concluded that the revenue-cap regulatory regime originally in place then did not allow full cost-recovery alone, given the high required investments for replacement and expansion of networks. They then suggested the change to the current cost-plus regime to regulate transmission investment costs.

However, other studies implicitly challenge the change to a cost-plus regime to regulate transmission investment costs (e.g., Weber et al, 2013). Such studies state that the current modified regime (cost-plus for new investment and revenue-cap for operation and maintenance) is not optimal since the TSOs tend to inflate costs and network capacity is not being increased where it is most needed; namely, in a north-tosouth corridor to bring into the populated southern consumption areas large amounts of wind power generated in the north. In fact, the regime seems to instead incent TSOs to connect lignite-power plants (and even overinvest in such connections), which seems a contradiction with the German large-scale renewable-integration policy goals.

A formal assessment of the regulatory incentives in the German electricitytransmission regime would require a comprehensive optimal welfare approach. In this paper we carry out a first step in that direction, by evaluating the associated incentives in the NEP transmission planning process. The German regime assumes scenarios for the evolution of generation capacity and technologies so as to determine network capacity expansions in transmission planning. However, an intuitive evaluation of this process suggests that the NEP might be a non-transparent transmission model and independently determined from the generation power-flow dispatch model. Additionally, the TSOs evidently determine the NEP knowing ex ante that they will be 
subject to cost-plus regulation. Therefore, since system-operation and ownership are integrated, the German TSOs have incentives to strategically determine capacity expansions and inflate costs, anticipating cost-plus regulation in expansion costs. As opposed to the ISO models discussed in 3.2 and 3.3, the German TSOs do not seem to be maximizing welfare, but rather strategically maximizing profits under market power and asymmetry of information.

The above somewhat crude naïve intuition should need to of course be confronted with a formal welfare-analysis that allows evaluate welfare losses associated with the proposed NEP specific network expansions. Such a model should first carry out a transition from the current German uniform-pricing scheme to a nodal-pricing regime so as to be able to gauge the shadow value of network congestions, and be able to evaluate welfare efficiency in expanding transmission links (as in Hogan et al, 2010). One step in that direction has already been done by Kunz et al (2014) (see fig. 2). ${ }^{16}$ This also implies a counterfactual where a hypothetical ISO maximizes welfare in an integrated transmission generation-dispatch power-flow model. The basic idea would be then to compare the actual network expansions proposed under NEP with the welfarebenchmark case simulations derived from this modeling strategy. We carry out this comparison in the next section.

\footnotetext{
${ }^{16}$ One important output of such transitional model would be the determination of FTRs which, among other things, might be used to model transmission point-to-point outputs in a welfare maximizing model (as in Hogan et al., 2010, and Rosellón and Weigt, 2011).
} 
Fig. 2

Average change in surplus of demand in the high wind winter week under volume-based allocation approach. Source: Kunz et al (2014), p. 18

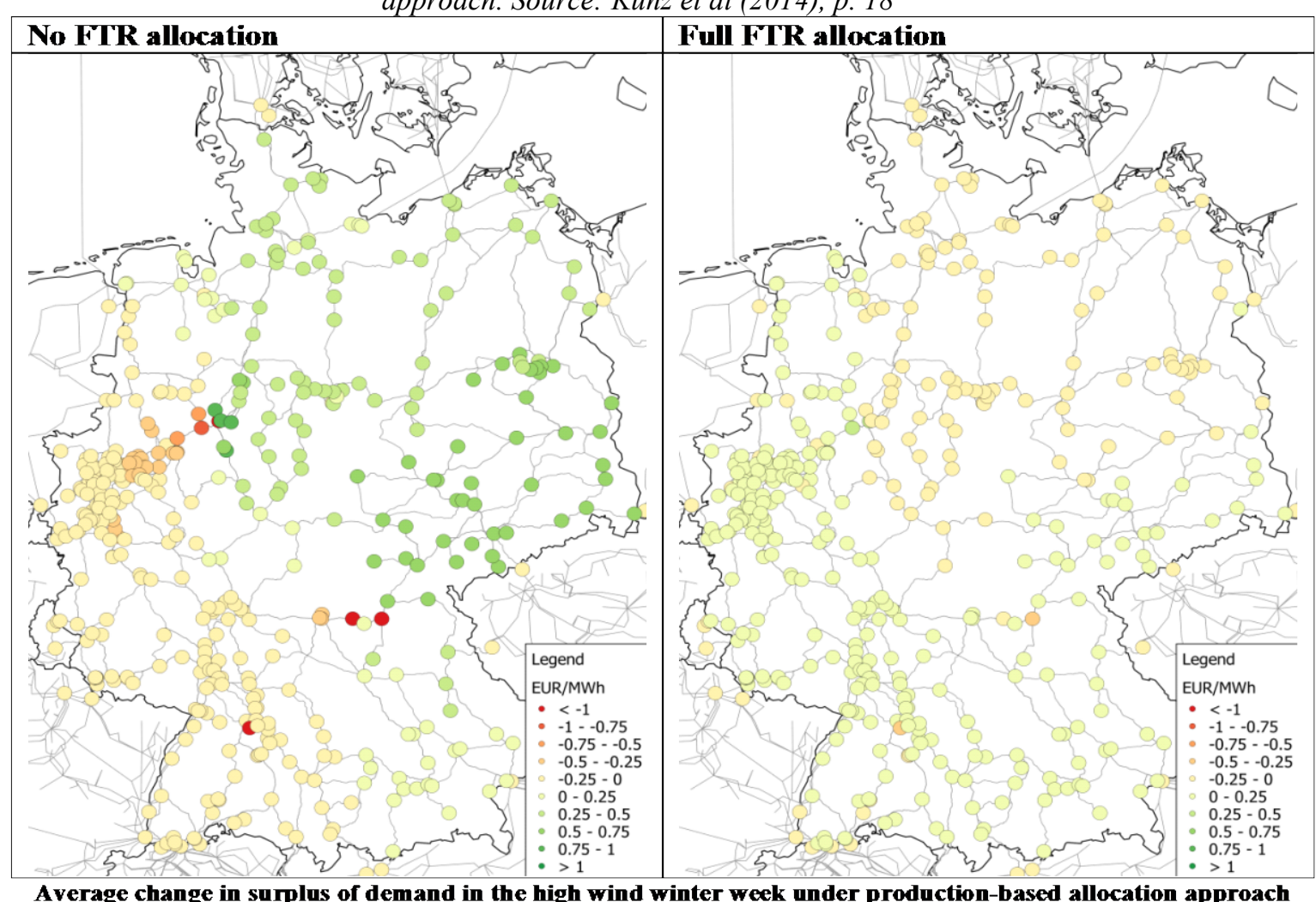

\subsection{A Transitional Model of Transmission Planning in Germany}

To quantify the required network expansion of the German electricity system, we employ a basic quantitative modelling approach. The model comprises an aggregated representation of the German power system which is optimized for an entire year. We consider two different regulatory settings with respect to their consideration of dispatch decisions and investment cost in the transmission planning cost, and analyze the implications on investment needs and system costs. The focus of this modeling strategy is to illustrate the existing incentives for excessive investment within the current regime in Germany, which decouples the generation capacity dispatch from their choice of network capacity expansions.

\subsubsection{Model description and data}

The underlying modelling approach is described by equations (1)-(5). The model determines the minimal-cost generation dispatch $G_{i, n}$ and network expansion $P_{l}$ subject to maximum generation limit of generation units (2), the nodal energy balance with 
fixed price-inelastic demand (3), and the capacity limitations of transmission lines (4). A DC load-flow approach is applied to capture the physical flow characteristics of electrical energy. Furthermore, we assume that load flow patterns are independent from network expansion in order to avoid arising non-linearities and reduce computational complexity.

$$
\begin{array}{cc}
\min \sum_{i, n} m c_{i, n} G_{i, n}+\sum_{l} c_{l}^{i n v} P_{l} & \\
0 \leq G_{i, n} \leq g_{i, n}^{\max } & \forall i, n \\
\sum_{i} G_{i, n}-q_{n}+N I_{n}=0 & \forall n \\
0 \leq\left|\sum_{n} p t d f_{l, n} N I_{n}\right| \leq \operatorname{cap}_{l}+P_{l} & \forall l \\
P_{l} \geq 0 &
\end{array}
$$

The model is optimized for 2035 on an hourly basis for an entire year $(8,760$ hours). The dataset comprises the current projections of the German power system for 2035 based on BNetzA (2014). These data are also used for the 2015 version of the $N E P$. This includes the expected development of generation capacities as well as projections on fuel and $\mathrm{CO}_{2}$ prices, and national load. As can be seen in Table 1, renewable capacities in Germany are expected to increase significantly while conventional capacities decline. 
Table 1

Projected development of German electricity capacities Source: BNetzA (2014), p. III

\begin{tabular}{lcc}
\hline in GW & $\mathbf{2 0 1 3}$ & $\mathbf{2 0 3 5}$ \\
\hline Nuclear & 12.1 & 0.0 \\
Lignite & 21.2 & 9.1 \\
Coal & 25.9 & 11.1 \\
Gas & 26.7 & 32.7 \\
Renewables & & \\
$\quad$ Hydro & 3.9 & 4.2 \\
$\quad$ Wind onshore & 33.8 & 88.8 \\
$\quad$ Wind offshore & 0.5 & 18.5 \\
$\quad$ Biomass & 6.2 & 8.4 \\
$\quad$ Solar & 36.3 & 59.9 \\
Pumped-hydro & 6.4 & 12.5 \\
storage & & \\
Other & 9.2 & 2.4 \\
\hline
\end{tabular}

Furthermore, the topology of the current transmission network as well as the spatial pattern of renewable generation and load are based upon Egerer et al. (2014). In order to reduce the computational complexity, a spatial aggregation of the transmission network and the spatial load and renewable data is performed. The aggregated dataset consists of 21 network nodes and 170 transmission lines and provides a detailed representation of transmission network. In order to capture the international exchanges with neighboring countries, European countries are considered on a national detail level with their estimated capacities and load based on ENTSO-E (2014).

\subsubsection{Simulation results and discussion}

The presented modelling approach allows us to quantify the implications of different regulatory settings on resulting network investments. Herein, the consideration of transmission investment cost within the $N E P$ approach is particularly interesting. The current NEP approach decouples the dispatch of generation capacity from the determination of network expansion needs. As the spot market pricing in German power system relies on uniform pricing approach, generation dispatch is determined without considering internal network restrictions. If congestion in the German transmission network occurs, it is managed by the TSOs using curative congestion management options (Kunz, 2013). Thus, TSOs currently have an incentive to optimize transmission investments to ensure the feasibility of the generation dispatch of the uniform pricing market, and reducing the need of congestion management. 
Therefore, the first scenario, decoupled, captures the characteristics of the current NEP approach by disregarding cost for (or assuming costless) network expansion. This assumption ensures that network expansion is optimized solely to implement a cost-minimal generation dispatch within Germany. A counterfactual second scenario, integrated, optimizes both generation dispatch and network expansion with their associated costs. The difference between both scenarios is in the consideration of the investment cost for network expansion.

Table 2 depicts the cost and capacity results of the two considered scenarios. In general, the significant increase of renewable generation capacities in Germany requires a reshaping of the existing transmission network in order to balance regional generation surplus and deficits. As a main share of renewable wind generation is expected in the northern part of the country (while load is mostly located in the western and southern part) transmission needs increase in particular from north to south. Considering a decoupled planning framework, as currently done within the German network planning, investment cost sum up to $15.4 \mathrm{bn}$. EUR relating to an increase of transmission capacity by $88.5 \mathrm{GW} .{ }^{17}$ In an integrated optimization setting, total investment cost amount to $8.5 \mathrm{bn}$. EUR corresponding to an additional capacity of $48.6 \mathrm{GW}$. Thus, investment needs could be significantly reduced up to $45 \%$ through an integrated optimization of generation dispatch and transmission investments.

Table 2

Investment cost and added capacity in the decoupled and integrated scenario.

\begin{tabular}{lcc}
\hline & Decoupled & Integrated \\
\hline $\begin{array}{l}\text { Transmission investment } \\
\text { cost in bn. EUR }\end{array}$ & 15.4 & 8.5 \\
Capacity added in GW & 88.5 & 48.6 \\
\hline
\end{tabular}

Fig. 3 illustrates the simulated transmission investment needs between the different regions in Germany for the two considered scenarios. In both scenarios, significant investments are required to integrate the increasing shares of renewable generation and to allow an instantaneous regional balancing of generation and load. Due to a strong increase of wind generation capacity in the northern part of Germany, additional transmission capacity on the north-south axis is of particular importance in both scenarios to supply load centers in western and southern parts of Germany.

\footnotetext{
${ }^{17}$ The German network development plan of 2014 (50Hertz et al., 2014) identifies an investment volume of approximately 23 bill. EUR. Investment costs of the simulation are lower, due to the aggregated representation of the German transmission network.
} 
However, both scenarios differ in the amount of investment needs which are lower in the integrated setting.

Fig. 3

Transmission capacity investments in Germany for 2035 in the decoupled and integrated scenario.

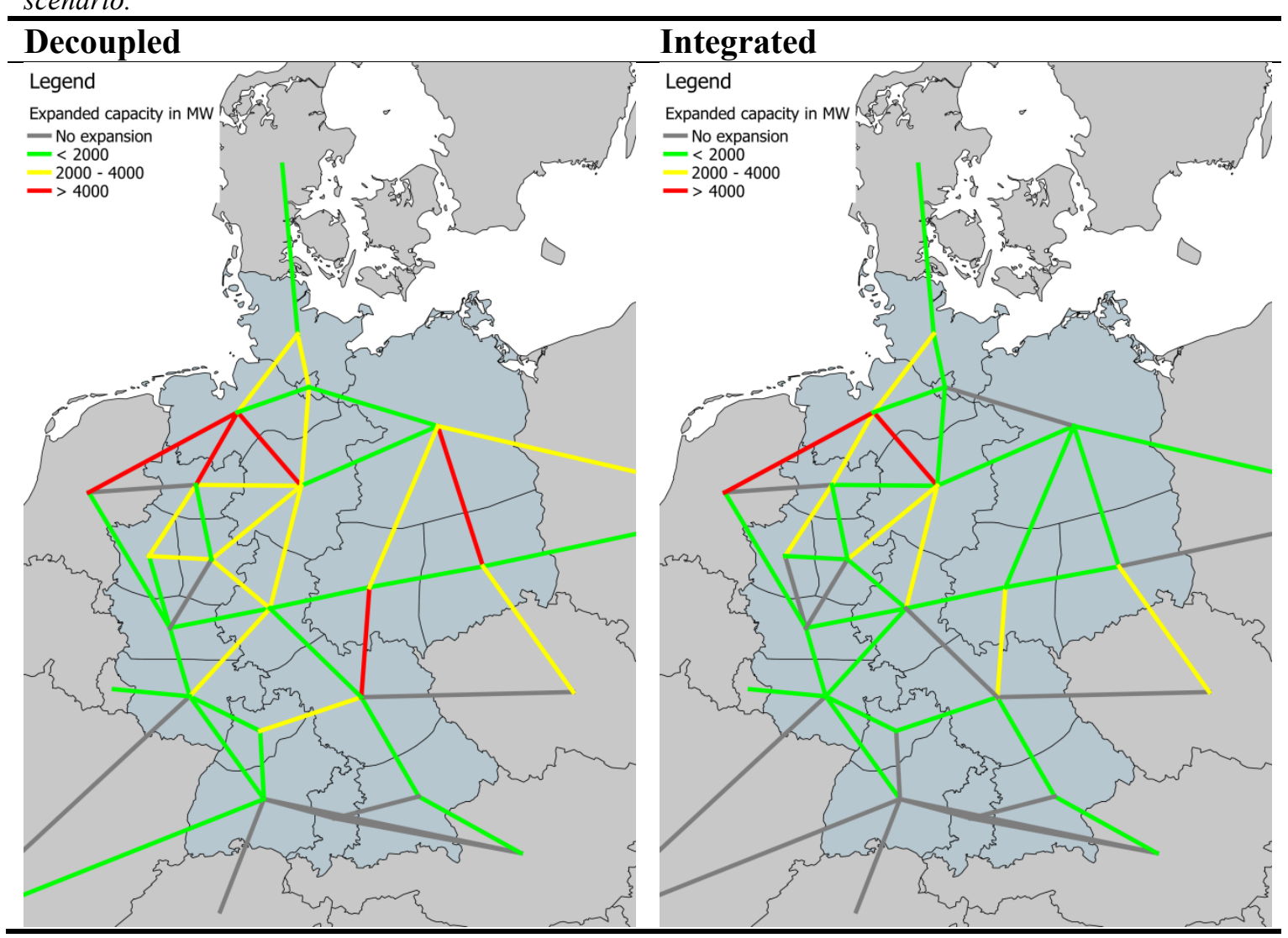

The savings in transmission investment needs basically stems from the fact that a change in the spatial generation pattern to circumvent congestion is less costly than expanding the corresponding transmission line. This effect then reduces the transmission need in particular in a few hours where either renewable wind generation is high. As can be seen in Fig. 3, network expansion in the north eastern part of Germany is reduced to a large extent if transmission costs are considered. Due to dominant renewable wind capacity in this region, the temporary reduction of peak wind generation in a few hours leads to significantly lower expansion needs to adjacent regions. Thus, integrating the amount of energy of these few hours by expanding the transmission network comes at higher cost than replacing renewable generation by other generation technologies. Furthermore, this effect also occurs between different conventional generation technologies leading to less investment needs.

Table 3 depicts the welfare distribution in Germany for the two considered cases. As we assume a fixed demand, consumer surplus is constructed assuming a value 
of lost load (VoLL) of 4000 EUR/MWh and the simulated prices for demand. Producer surplus comprises the profits from selling energy at market prices. Finally, the surplus of the transmission operator accounts for congestion revenues ${ }^{18}$ and annualized investment cost in the different scenarios. The sum of the three surpluses is defined as the total welfare of the German power system for an entire year. Through an integrated evaluation of costs and benefits of transmission capacity investments, total welfare can be increased by 1.3 bn. EUR or $0.1 \%$.

Due to the integrated assessment of generation dispatch and network investments, we implicitly allow for regional price differences in the spot market. This leads on the one hand to higher cost for consumers and thus less surplus. On the other hand, producer face higher profits for the same reasoning. Furthermore, the TSO faces congestion rents in the integrated case which overcompensate the annualized investments cost. In combination with the lower amount of transmission investments, the increase in surplus of producers and TSOs exceeds the reduction in consumer's surplus yielding an increase of total welfare. Therefore, an integrated evaluation of cost for investments and benefits of added transmission capacity reduces the amount of transmission investments, and enhances the welfare of the entire system.

In our simulations, the benefits of added transmission capacity are determined within the spot market dispatch which allows for regional price differences. Alternatively, benefits could also be defined as a reduction in the usage of congestion management measures which are done by the TSO after a uniformly priced spot market. This approach is more consistent with current European market organization. However, as shown in Kunz (2013), this would mainly impact the distribution of surplus between market participants. The efficiency of the generation dispatch and therefore the total welfare would remain unaffected. Therefore, the welfare benefits would also accrue in a system with a uniformly priced spot market and curative congestion management.

Table 3

Consumer, producer, and TSO surplus in the decoupled and integrated scenario

\begin{tabular}{lcc}
\hline & Decoupled & Integrated \\
\hline $\begin{array}{l}\text { Consumer surplus in bn. } \\
\text { EUR }\end{array}$ & $2,147.0$ & $2,145.5$ \\
Producer surplus in bn. & 10.6 & 11.5 \\
EUR & & 0.9 \\
TSO surplus in bn. EUR & -1.0 & $\mathbf{2 , 1 5 8 . 0}$ \\
Total welfare in bn. EUR & $\mathbf{2 , 1 5 6 . 6}$ & \\
\hline
\end{tabular}

\footnotetext{
${ }^{18}$ Congestion revenues stemming from international trade are excluded in both scenarios.
} 


\section{Conclusions}

Our qualitative overall assessment of both the German planning and regulatory regimes suggests that the German TSOs have incentives to strategically determine capacity expansions and inflate costs. The German TSOs do not seem to be maximizing welfare, but rather strategically maximizing profits anticipating cost-plus regulation in expansion costs.

Our formal analysis of the NEP further shows that the German TSOs have in general incentives to inefficiently overinvest as compared to a model that integrates both transmission expansion decisions and generation dispatch. The amount of over investment was measured in a transitional model for Germany, where we constructed a counterfactual with nodal prices. The results of our simulations show that investment needs could be significantly reduced up to $45 \%$, and welfare enhanced in $1.3 \mathrm{bn}$. EUR, through an integrated optimization of generation dispatch and transmission investments. Considering the benefits and costs of transmission expansion in the determination of transmission investment needs then avoids inefficient overinvestments in network infrastructure and enhances welfare of the entire system. If investment costs are disregarded in this process the network is designed to be congestion-free in all considered hours. This planning approach is in particular questionable in systems with high shares of renewable generation and consequently high temporary generation peaks in specific regions, as it may create significant overinvestments in transmission infrastructure.

In future work the combined German revenue-cap cost-plus transmission regulatory scheme could be formally analyzed. This would be achieved through a subsequent modeling step where this regime is contrasted with an alternative one that is subject to pure price-cap regulation over all transmission costs. Building on the integrated lower-level program already achieved in this paper, an upper-level programming model could be set up where the transmission company maximized its flow of profits subject to revenue-cap on operation and maintenance costs and cost-plus regulation for expansion costs. As in Schill et al. (2015) and Egerer et al. (2015), detailed simulations under this last model might then be contrasted (in terms of welfare) with the HRV bi-level programming model, where price-cap regulation would be applied to both investment costs and operation-maintenance costs. 


\section{References}

50Hertz Transmission, Amprion, TenneT TSO, TransnetBW (2012), $\begin{array}{lllll}\text { Netzentwicklungsplan } & \text { Strom 2012, } & 15 & \text { August }\end{array}$ http://www.netzentwicklungsplan.de/.

50Hertz Transmission, Amprion, TenneT TSO, TransnetBW (2014), Netzentwicklungsplan Strom 2014, zweiter Entwurf, 4 November 2014, http://www.netzentwicklungsplan.de/.

Adamson, S. and G. Parker (2013) "Participation and Efficiency in the New York Financial Transmission Rights Market," in Rosellón, J. and T. Kristiansen (eds.), Financial Transmission Rights: Analysis, Experiences and Prospects, Lecture Notes in Energy 7, Springer Verlag, 2013, ISBN: 978-1-4471-4786-2.

Brito, D.L. and J. Rosellón (2011), “Lumpy Investment in Regulated Natural Gas Pipelines: an Application of the Theory of the Second Best," Networks and Spatial Economics, 11:533-553.

Brunekreeft G. and J. Borrmann (2011), "The Effect of Monopoly Regulation on the Timing of Investment“, Bremen Energy Working Papers, No. 9 Feb., Jacobs University Bremen.

BNetzA (2014), Szenariorahmen 2025: Genehmigung, Bundesnetzagentur (Federal Network Agency for Electricity, Gas, Telecommunications, Post and Railway), http://www.netzausbau.de/SharedDocs/Downloads/DE/Delta/Szenariorahmen/Szenarior ahmen 2025 Genehmigung.pdf? blob=publicationFile .

Crew, M. A. \& Kleindorfer, P. R. (1996), "Incentive Regulation in the United Kingdom and the United States: Some Lessons", Journal of Regulatory Economics, 9:3, 211-225.

DENA-Verteilnetzstudie (2012), (Brunekreeft, Rehtanz, et.al., 2012) http://www.dena.de/projekte/energiesysteme/verteilnetzstudie.html

Egerer, J., J. Rosellón and W-P. Schill (2015), "Power System Transformation toward Renewables: An Evaluation of Regulatory Approaches for Network Expansion," The Energy Journal, Vol. 36 (4).

Egerer, J. and W-P Schill (2014), "Power System Transformation toward Renewables: Investment Scenarios for Germany," Economics of Energy and Environmental Policy," vol. 3, no.2. 
Egerer, J., C. Gerbaulet, R. Ihlenburg, F. Kunz, B. Reinhard, C. von Hirschhausen, A. Weber, J. Weibezahn (2014), "Electricity Sector Data for Policy-Relevant Modeling: Data Documentation and Applications to the German and European Electricity Markets", Data Documentation of DIW Berlin 72, German Institute for Economic Research.

ENTSO-E (2014), Scenario Outlook \& Adequacy Forecast 2014-2030, Brussels, Belgium.

Hogan, W., J. Rosellón, and I. Vogelsang (2010), Toward a Combined MerchantRegulatory Mechanism for Electricity Transmission Expansion, Journal of Regulatory Economics, 38(2), 113-143.

Kristiansen, T. and J. Rosellón (2006), “A Merchant Mechanism for Electricity Transmission Expansion”, Journal of Regulatory Economics, 29(2), 167-193.

Kunz, F. (2013), "Improving Congestion Management: How to Faciliate the Integration of Renewable Generation in Germany”, Energy Journal, 34 (4), 55-78.

Kunz, F., K. Neuhoff and J. Rosellón (2014). "FTR Allocations to Ease Transition to Nodal Pricing: An Application to the German Power System," Discussion Papers of DIW Berlin 1418, German Institute for Economic Research.

Jamasb, T. \& Pollitt, M. (2001), "Benchmarking and Regulation: International Electricity Experience”, Utilities Policy, 9:3, 107-130.

Lanz, B. (2005), “Two-part pricing under revenue cap regulation”, FE-reports, nr 408, Göteborg University, School of Business, Economics and Law (https://gupea.ub.gu.se/bitstream/2077/2606/1/gunwba408.pdf).

Léautier, T.-O. (2000), Regulation of an electric power transmission company, The Energy Journal, 21, 61-92.

Léautier, T.-O. and V. Thelen (2009), "Optimal expansion of the power transmission grid: why not?," Journal of Regulatory Economics, 36 (2), 127-153.

Pollit, M. (2012), "Lessons from the history of independent system operators in the energy sector," Energy Policy, 47, 32-48.

Rosellón, J. and H. Weigt (2011), "A dynamic incentive mechanism for transmission expansion in electricity networks - Theory, modeling and application", The Energy Journal, 32(1), 119-148.

Rosellón, J., Z. Myslíková and E. Zenón (2011), ““'Incentives for transmission investment in the PJM electricity market: FTRs or regulation (or both?)," Utilities Policy, Volume 19, Issue 1, January, Pages 3-13. 
Schill, W.-P., J. Egerer, and J. Rosellón (2015), “Testing Regulatory Regimes for Power Transmission Expansion with Fluctuating Demand and Wind Generation." Journal of Regulatory Economics, vol. 47, issue 1, February.

Tanaka, M. (2007), Extended Price Cap Mechanism for Efficient Transmission Expansion under Nodal Pricing, Network and Spatial Economics, 7, 257-275.

Vogelsang, I. (2001), "Price regulation for independent transmission companies", Journal of Regulatory Economics, 20 (2), 141-65.

Weigt H., T. Jeske, F. Leuthold, and C. von Hirschhausen (2010). Take the long way down: Integration of largescale North Sea wind using HVDC transmission. Energy Policy, 38(7): 3164-73.

Weber A., Beckers T., Behr P., Bieschke N., Fehner S., and von Hirschhausen C. (2013), "Long-term Power System Planning in the Context of Changing Policy Objectives - Conceptual Issues and Selected Evidence from Europe,” mimeo prepared for the Smart Energy for Europe Platform (SEFEP) by Workgroup for Infrastructure Policy (WIP), Berlin University of Technology, June (available at:

https://www.wip.tu-

berlin.de/fileadmin/fg280/forschung/publikationen/2013/weber_et_al_2013-

long term power system planning SEFEP.pdf) 